\title{
Membrane Omega-3 Fatty Acid Deficiency as a Preventable Risk Factor for Comorbid Coronary Heart Disease in Major Depressive Disorder
}

\author{
Robert K. McNamara \\ Department of Psychiatry, University of Cincinnati College of Medicine, Cincinnati, OH 45267, USA
}

Correspondence should be addressed to Robert K. McNamara, robert.mcnamara@uc.edu

Received 11 May 2009; Accepted 10 July 2009

Recommended by Radmila M. Manev

Major depression disorder (MDD) significantly increases the risk for coronary heart disease (CHD) which is a leading cause of mortality in patients with MDD. Moreover, depression is frequently observed in a subset of patients following acute coronary syndrome (ACS) and increases risk for mortality. Here evidence implicating omega-3 (n-3) fatty acid deficiency in the pathoaetiology of CHD and MDD is reviewed, and the hypothesis that n-3 fatty acid deficiency is a preventable risk factor for CHD comorbidity in MDD patients is evaluated. This hypothesis is supported by cross-national and cross-sectional epidemiological surveys finding an inverse correlation between n-3 fatty acid status and prevalence rates of both CHD and MDD, prospective studies finding that lower dietary or membrane EPA+DHA levels increase risk for both MDD and CHD, case-control studies finding that the n-3 fatty acid status of MDD patients places them at high risk for emergent CHD morbidity and mortality, meta-analyses of controlled n-3 fatty acid intervention studies finding significant advantage over placebo for reducing depression symptom severity in MDD patients, and for secondary prevention of cardiac events in CHD patients, findings that n-3 fatty acid status is inversely correlated with other documented CHD risk factors, and patients diagnosed with MDD after ACS exhibit significantly lower $n-3$ fatty acid status compared with nondepressed ACS patients. This body of evidence provides strong support for future studies to evaluate the effects of increasing dietary n-3 fatty acid status on CHD comorbidity and mortality in MDD patients.

Copyright (C) 2009 Robert K. McNamara. This is an open access article distributed under the Creative Commons Attribution License, which permits unrestricted use, distribution, and reproduction in any medium, provided the original work is properly cited.

\section{Introduction}

In the year 2000, the World Health Organization (WHO) identified major depressive disorder (MDD) as the fourth ranked cause of disability and premature death globally and projected that by $2020 \mathrm{MDD}$ and ischemic heart disease will be the two most important causes of disability worldwide $[1,2]$. These global trends suggest that the prevalence rates of MDD and coronary heart disease (CHD) are increasing in parallel, and emerging data suggest a high degree of symptomatic comorbidity. Specifically, meta-analyses and systematic reviews of epidemiological evidence support the following: (1) clinical depression is an independent risk factor for the development of CHD, (2) severity of depression is positively correlated with CHD risk, (3) a subset of patients with CHD (20-30\%) exhibit comorbid depression,
(4) depressive symptoms increase secondary cardiovascular events and mortality in CHD patients, and (5) CHD is a leading cause of excessive mortality in MDD patients, particularly among women [3-9]. The high rate of CHD comorbidity in MDD is therefore suggestive of a common underlying pathoaetiological mechanism(s).

The pathoaetiology of MDD [10-12] and CHD [13-16] involves both genetic and environmental factors, and both genetic and environmental risk factors have been proposed to account for their comorbidity [17]. A rapidly emerging body of evidence suggests that membrane omega-3 (n-3) fatty acid deficiency is a preventable risk factor for both CHD [18] and MDD [19]. Based on this body of evidence, a scientific advisory panel convened by the American Psychiatric Association (APA) recommended that patients with affective disorders including MDD increase their daily 
EPA+DHA intake to $1 \mathrm{~g} / \mathrm{d}$ [20], a daily dose previously endorsed by the American Heart Association (AHA) [21]. Although this evidence was obtained from studies conducted largely in parallel in the fields of cardiology and psychiatry, the potential contribution of n-3 fatty acid deficiency to increased CHD morbidity and mortality in MDD has been postulated previously $[22,23]$. Nevertheless, a large body of evidence has emerged subsequently that permits a reevaluation of this potential interrelationship.

To evaluate the hypothesis that n-3 fatty acid deficiency is a risk factor for CHD morbidity and mortality in MDD, it is important to consider that the age at onset for unipolar and bipolar depression peaks in young adulthood (15-19 years) $[24,25]$, whereas CHD mortality peaks substantially later (75-84 years) [26]. Therefore, this hypothesis would additionally posit that cerebral hypoperfusion and depressed mood $[27,28]$ are early manifestations of cardiovascular insufficiency associated with n-3 fatty acid deficiency [29, 30 ], and the progressive deterioration of cardiovascular and cerebrovascular integrity over the lifespan increases risk for CHD morbidity and mortality in older patients with MDD [31]. Accordingly, this hypothesis predicts that optimization of n-3 fatty acid status and associated cardiovascular and cerebrovascular integrity prior to onset will be an efficacious preventive strategy for both MDD and CHD.

\section{Omega-3 Fatty Acid Biosynthesis and Membrane Accrual}

As background, mammals are incapable of synthesizing n-3 fatty acids de novo and are therefore entirely dependent on dietary sources to procure and maintain adequate concentrations in peripheral and central phospholipid membranes. Dietary sources of the vegetable n-3 fatty acid precursor $\alpha$ linolenic acid (ALA, 18:3n-3) include flaxseed, rape, linseed, canola, soy, and perilla oils. The biosynthesis of eicosapentaenoic acid (EPA, 20:5n-3) and docosahexaenoic acid (DHA, 22:6n-3) from ALA requires a series of microsomal elongation and delta-5 and delta- 6 desaturase-mediated reactions $[32,33]$, and the final synthesis of DHA requires additional conversions within peroxisomes [34] (Figure 1). Nevertheless, preformed EPA and DHA can be obtained directly from the diet, including salmon, sardines, trout, and tuna, seafood and supplements, thereby bypassing this biosynthetic pathway. Delta-5 (FADS1) and delta-6 (FADS2) desaturase genes are colocalized to chromosome 11 (11q1213.1), and are highly expressed in liver, heart, and brain [35-38]. The expression and activities of these enzymes are regulated by multiple factors including dietary $\mathrm{n}-3$ fatty acid intake $[35,36,39]$, gonadal hormones [40-42], and insulin [43]. Furthermore, the biosynthesis of $n-6$ fatty acids from the dietary precursor linoleic acid (LA, 18:2n-6) utilizes the same enzymatic pathway in a competitive manner (Figure 1). Accordingly, dietary deficits in ALA (18:3n-3) are associated with a significant increase in $\mathrm{n}-6$ fatty acid biosynthesis from dietary LA [44, 45], and western diets which have a high LA content are associated with limited $(<1.0 \%)$ EPA and DHA biosynthesis from ALA [46-50].
Emerging data also indicate that common single nucleotide polymorphisms in FADS1 and FADS2 genes are an important determinant of RBC, plasma, and breast milk n-3 and n-6 fatty acid composition [51-54]. For example, a case-control study found that subjects carrying FADS haplotypes and consuming a Western diet exhibit a higher index of n-6 fatty acid biosynthesis (arachidonic acid : LA ratio), and this index was an independent risk factor for coronary artery disease [55]. Taken collectively, these findings indicate that membrane $n-3$ and n-6 fatty acid composition is governed by both environmental (dietary n6/n-3 fatty acid ratio) and genetic factors.

\section{Epidemiology}

There are large cross-national variations in per capita fish/seafood consumption, a surrogate for EPA+DHA intake. For example, annual seafood consumption in Japan ( $148 \mathrm{lb} /$ person) is approximately 3 -fold higher than in the USA (48 lb/person) [56], and this is reflected in a $\sim 2$-fold greater red blood cell (RBC) membrane EPA+DHA composition in Japanese adults $(8.5 \pm 1.8 \%)$ [57] compared with USA adults (4.9 $\pm 2.1 \%)$ [58]. Moreover, there are large crossnational variations in the lifetime prevalence rates of MDD and CHD mortality. For example, life-time prevalence rates of MDD in Japan $(<3 \%)[59,60]$ are $\sim 6$-fold lower than in the USA (16.2\%) [61], and the prevalence of CHD mortality among Japanese men aged 55-64 years $(58 / 100000)$ is 6fold lower than among American white men in the USA (345/100 000) [62]. Across multiple countries, there is a significant inverse correlation between per capita fish or seafood consumption and the lifetime prevalence rates of unipolar depression [63, 64], bipolar depression [65], and postpartum depression [66]. Together, these data suggest that cross-national variations in n-3 fatty acid intake are inversely correlated with the prevalence of MDD and CHD mortality. However, the potential contribution of other nutrients found in fish/seafood and other cultural and genetic differences preclude definitive evaluation of their interrelationship.

On a smaller scale, cross-sectional studies have also observed an inverse relationship between dietary n-3 fatty acid intake and prevalence rates of MDD, and that this relationship is stronger among women [67-72]. For example, the Northern Finland 1966 birth cohort study, a prospective survey of 2721 males and 2968 females adults (age: 31 years), found that the risk of developing depression increased 2.6fold among females, but not males, who were rare fish eaters (monthly) compared with regular (weekly) fish eaters [72]. Moreover, a cross-sectional survey of 9806 male and 12029 female adult and elderly subjects (40-74 years) from Norway found that subjects who ingested cod liver oil on a daily basis (DHA: 300-600 mg/d, EPA: 300-600 mg/d) were significantly less likely to have depressive symptoms than nonusers after adjusting for multiple confounding factors [70]. Similarly, cross-sectional surveys have found an inverse correlation between dietary n-3 fatty acid intake and CHD risk factors, nonfatal acute coronary syndrome (ACS), and sudden cardiac death (SCD) $[73,74]$. Lastly, shifting diets 


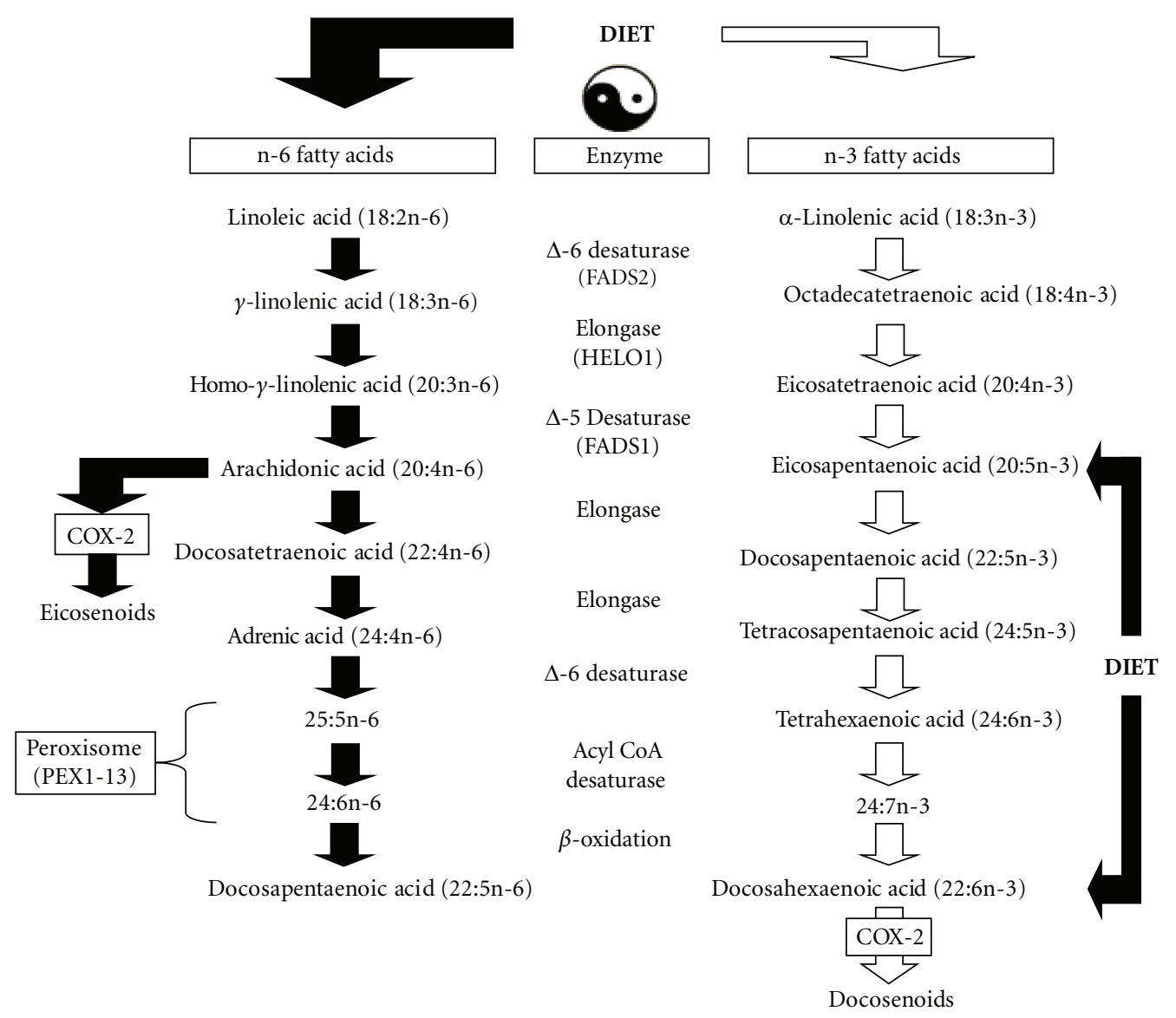

FIGURE 1: Diagram illustrating the biosynthetic pathway of n-3 and n-6 fatty acids from dietary precursors. The biosynthesis of EPA (20:5n3 ) and DHA (22:6n-3) from dietary $\alpha$-linolenic acid (18:3n-3), and arachidonic acid (20:4n-6) from linoleic acid (18:2n-6), requires a series of common and competitive microsomal elongation and delta-5 and delta- 6 desaturase-mediated reactions. The final synthesis of DHA requires additional modifications within peroxisomes. Preformed DHA (22:6n-3), the principle membrane esterified n-3 fatty acid, and EPA can be obtained directly from the diet. COX-2 mediated metabolism of DHA and arachidonic acid yields anti-inflammatory docosenoids and proinflammatory eicosanoids, respectively. Because the n-6 and n-3 arms compete for common biosynthetic enzymes, elevations in the dietary LA : ALA ratio increase n-6 fatty acid biosynthesis (reflected as reductions in membrane LA and elevations in downstream fatty acid metabolites) and reduced n-3 fatty acid biosynthesis from ALA (reflected as reductions in membrane EPA+DHA).

in Arctic populations away from fish-based to western diets have been associated with increased rates of both depression and CHD [75].

\section{Prospective Longitudinal Observational Studies}

Another approach taken to evaluate the contribution of n-3 fatty acid status to the pathoaetiology of MDD and $\mathrm{CHD}$ is prospective longitudinal observational studies using baseline dietary n-3 fatty acid intake or membrane n-3 fatty acid composition as the predictor variable. In one of the largest prospective studies conducted to date, EPA+DHA intake was determined at baseline in 3317 young adult men and women (mean age: 32 years) residing in the USA, and depressive symptoms determined at a 10-year follow-up. It was found that among both men and women, the highest quartile of EPA+DHA intake at baseline was associated with a lower adjusted risk for depression at 10 years relative to the lowest quintile, and this association was stronger in women [76]. Other studies have evaluated membrane n-3 fatty acid status and the emergence of perinatal depression in pregnant women. In a recent prospective case-control study of depressed and nondepressed women, it was found that higher plasma DHA and total n-3 fatty acid composition in the third trimester were associated with a significantly lower adjusted risk for depression [77]. In this study, women with the lowest plasma n-3 fatty acid levels were six times more likely to be depressed than women who had the highest $n-3$ fatty acid levels. Similarly, another study found that low or no n-3 fatty acids intake from fish/seafood were associated with a higher incidence perinatal depression relative to the highest quartiles of $n-3$ fatty acids intake [78]. A third study found that faster recovery of plasma DHA content postpartum was associated with reduced risk of postpartum depression [79]. Together, these findings provide prospective evidence for an inverse and independent 
relationship between n-3 fatty acid status and the emergence of clinical depression.

Several large prospective longitudinal studies have evaluated the relationship between baseline n-3 fatty acid status and the emergence of CHD mortality. In the Physicians' Health Study, a prospective case-control study of 14,916 healthy adult male physicians (aged 25-74 years) found that 94 men experienced sudden cardiac death (SCD) over the following 17 years. Whole blood long-chain n-3 fatty acid composition in SCD cases was compared with 184 demographically matched controls. It was found that the adjusted risk for SCD was reduced by $80 \%$ in subjects with the highest blood n-3 fatty acid levels compared with those with the lowest levels [80]. In a similar study, 334 adult (aged 25-74 years) patients with primary cardiac arrest were compared with 493 control cases and controls free of prior CHD. It was found that subjects with a red blood cell (RBC) EPA+DHA composition of $3.3 \%$ exhibited a $70 \%$ greater adjusted risk for primary cardiac arrest compared with those with a RBC EPA+DHA composition of 5.0\% [81]. Similarly, in a cohort of 94 subjects with ACS and 94 age-, gender-, and race-matched controls, whole blood $\mathrm{EPA}+\mathrm{DHA}$ composition in ACS patients was 29\% lower than in controls, and the adjusted odds ratio for ACS was 0.67 [82]. The Nurses' Health Study, a prospective analysis of 84688 women (aged 34-59 years) without evidence of prior CHD and followed for up to 16 years, found that women who rarely ate fish $(<1$ per month) had a higher risk of CHD death compared with women with a higher intake of fish, with adjusted relative risks $(\mathrm{RR})$ of $1.0,0.93,0.78,0.68$, and 0.67 across intake quintiles [83]. Lastly, a meta-analysis of 13 cohorts including 222364 subjects followed for a mean of 11.8 years found that subjects with low or no n-3 fatty acids intake from fish/seafood experienced greater CHD mortality compared with individuals with a higher intake of fish [84]. The adjusted RRs for CHD mortality decreased with increasing fish intake frequency: 1-3 times per month (RR: 0.89 ), once per week (RR: 0.85), 2-4 times per week (RR: 0.77), and 5 or more times per week (RR: 0.62 ). Each $20 \mathrm{~g} / \mathrm{d}$ increase in fish intake was related to a $7 \%$ decreased risk of $\mathrm{CHD}$ mortality.

Together, these data indicate that low or no EPA+DHA intake is an independent risk factor for both CHD and MDD. However, only one prospective longitudinal study has evaluated the interrelationship between baseline n3 fatty acid intake, baseline depressive symptom severity, and the emergence of CHD. The Zutphen Elderly Study, a prospective cohort study conducted in 332 elderly men (aged 70-90 years) residing in the Netherlands, found that higher baseline dietary EPA+DHA intake (mean: $407 \mathrm{mg} / \mathrm{d}$ ) was associated with a 54\% lower adjusted risk for mild to severe depression relative to lower dietary EPA+DHA intake (mean: $21 \mathrm{mg} / \mathrm{d}$ ). However, baseline dietary EPA+DHA intake was not associated with a significant difference in the adjusted risk for CHD mortality during the 10-year followup period [85]. The authors concluded that these data do not support the hypothesis that lower n-3 fatty acid intake can account for the relationship between depression and CHD.

\section{Controlled n-3 Fatty Acid Intervention Trials}

A method used to evaluate the causal relationship between n-3 fatty acid status and the pathophysiology of MDD and $\mathrm{CHD}$ is double blind randomized placebo-controlled n3 fatty acid intervention trials. The results of randomized controlled n-3 fatty acid intervention trials in patients with unipolar or bipolar depression have been systematically reviewed previously $[19,20,86-90]$. Despite small sample sizes, negative trials, heterogeneity in study design in terms of daily n-3 fatty acid dose, type of n-3 fatty acid intervention (DHA, EPA, EPA+DHA), EPA : DHA ratio, intervention duration, concomitant medication effects, and depression symptom severity at baseline, independent meta-analyses have found a significant advantage of $n-3$ fatty acid treatment over placebo in patients with clinical depression $[20,86$, $87,90]$. Importantly, the majority of patients in these trials were being administered antidepressant or moodstabilizer medications, which may have blunted the effect size associated with the n-3 fatty acid intervention. For example, a preliminary randomized, double-blind placebocontrolled trial found that chronic dietary n-3 fatty acid $(\mathrm{EPA}+\mathrm{DHA})$ monotherapy significantly reduced symptom severity in pediatric and adolescent (8-12 years) patients with MDD [91]. Independent meta-analyses have also found a significant advantage of n-3 fatty acid treatment over placebo or usual care for event-free survival in patients with established CHD $[92,93]$. In one of the largest studies conducted to date, the Japan EPA Lipid Intervention Study found that the risk for nonfatal major cardiac events in a cohort of 18645 hypercolecterolemic men and women with or without a history of CHD was reduced by 19 percent in patients treated with EPA plus statin compared with statin alone [94]. Together, these secondary prevention studies provide evidence that depression symptom severity and CHD risk are both significantly attenuated by increasing n-3 fatty acid status. To date, however, there have been no controlled n-3 fatty acid primary prevention (monotherapy) trials conducted in subjects at risk for CHD or MDD, nor have there been primary prevention trials evaluating cardiac outcomes in MDD patients.

\section{Membrane n-3 Fatty Acid Composition Studies}

Case-control studies have compared the n-3 fatty acid status of patients with demographically similar healthy controls using plasma, RBC, and adipose n-3 fatty acid composition. Importantly, $\mathrm{RBC}$ membrane $\mathrm{EPA}+\mathrm{DHA}$ composition is highly correlated with habitual dietary EPA+DHA intake and plasma phospholipid EPA+DHA composition [95, 96]. Moreover, RBC membrane EPA+DHA composition is highly correlated human myocardium biopsy EPA+DHA composition [97] and primate frontal gray matter biopsy DHA composition [98]. Based on prior prospective longitudinal data reviewed above, RBC EPA+DHA composition (termed the "omega-3 index") has been proposed as a novel risk biomarker for CHD mortality, and risk zones have been 
TABLE 1: Omega-3 index in patients with MDD.

\begin{tabular}{|c|c|c|c|c|c|}
\hline Study & Country & Blood fraction & Sample size (case : control) & Omega-3 index ${ }^{1}$ (case : control) & $\Delta$ \\
\hline Maes et al. [103] & Belgium & Plasma & $36: 24$ & $3.6: 3.8$ & $-5 \%$ \\
\hline Maes et al. [104] & Belgium & Plasma & $34: 14$ & $4.5: 4.9$ & $-7 \%$ \\
\hline Tiemeier et al. [107] & Netherlands & Plasma & $106: 461$ & $4.4: 4.6$ & $-4 \%$ \\
\hline Peet et al. [106] & U.K. & $\mathrm{RBC}$ & $15: 15$ & $3.6: 6.3$ & $-42 \%$ \\
\hline Edwards et al. [102] & U.K. & $\mathrm{RBC}$ & $14: 10$ & $3.8: 5.4$ & $-31 \%$ \\
\hline McNamara et al. [105] & U.S. & $\mathrm{RBC}$ & $17: 20$ & $3.8: 4.8$ & $-21 \%$ \\
\hline Total & - & - & $218: 548$ & $3.9: 5.0$ & $-21 \%$ \\
\hline
\end{tabular}

$\triangle=$ Mean percent difference from controls

${ }^{1}$ Mean EPA+DHA wt $\%$ total fatty acid composition.

defined [99]. Specifically, RBC EPA+DHA composition of $<4 \%$ is high risk, $4 \%-8 \%$ is intermediate risk, and $>8 \%$ is low risk. An "omega- 3 index" of $\leq 4 \%$ is associated with a 10 -fold greater risk for SCD compared to an omega-3 index of $>8 \%$ [99]. Additionally, RBC EPA+DHA composition is significantly lower in patients with acute coronary syndrome (ACS) compared with age-, sex-, and race-matched controls [100], and a meta-analysis of prospective studies found that RBC DHA composition was inversely correlated with CHD events [101].

In the last 20 years there have been at least 6 published case-control studies from developed western countries that have compared peripheral (plasma, RBC) n-3 fatty acid composition in MDD patients and healthy controls. In all of these studies, significantly lower plasma or RBC EPA+DHA composition was observed in MDD patients relative to healthy controls [102-107] (Table 1). In a small case-control study conducted in the USA, we recently found that young adult MDD patients ( $n=17$, mean age: 35 years) exhibited RBC EPA+DHA composition that was significantly lower than healthy adult controls $(n=20$, mean age: 35 years) $(3.8 \% \pm 1.0 \%$ versus $4.8 \pm 1.1 \%, P=.006)$ [105]. In this cohort, $65 \%$ of MDD patients exhibited an RBC EPA+DHA index of $\leq 4.0 \%$ compared with $25 \%$ of controls. Analysis of combined case-control studies indicates that MDD patients $(n=548)$ exhibit $\mathrm{RBC}$ or plasma $\mathrm{EPA}+\mathrm{DHA}$ values that are $21 \%$ lower than healthy controls $(n=218)(3.9 \pm 0.4 \%$ versus $5.0 \pm 0.8 \%, P=.01$ ) (Table 1). These findings are significant because they suggest that patients with MDD exhibit an RBC $\mathrm{EPA}+\mathrm{DHA}$ index that is similar to that observed in patients with ACS $(3.4 \pm 1.6 \%)$ [100] and, based on prospective observational studies, suggests that at least a subset of MDD patients are in the high-risk $(\leq 4.0 \%)$ category for SCD [99]. Specifically, these data suggest that MDD patients have a $\sim 60 \%$ greater risk for primary cardiac arrest compared with healthy controls [81] and a 10-fold greater risk for SCD compared to adult Japanese subjects (Figure 2).

To date there have been three studies that have determined the interrelationship between $\mathrm{n}-3$ fatty acid status and depression in patients with established CHD. In the first study, ACS patients diagnosed with MDD exhibited significantly lower plasma EPA+DHA levels compared with nondepressed ACS patients [108]. In a second study, ACS patients with current depression had significantly lower mean plasma total n-3 fatty acid and DHA compared with

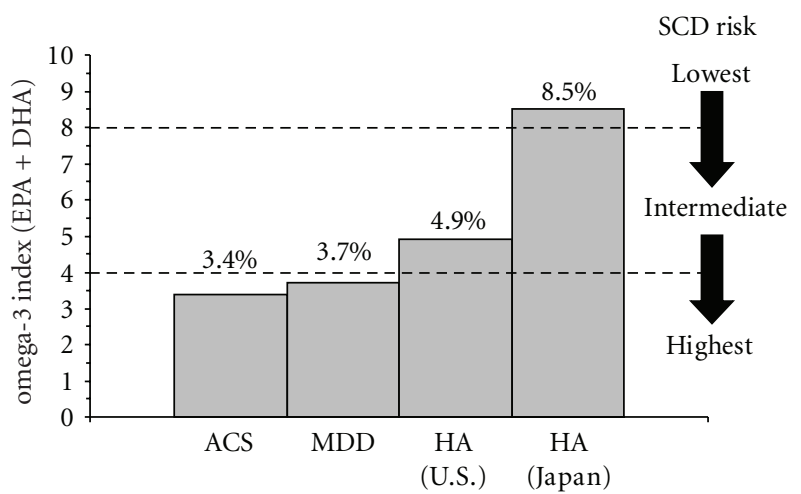

Figure 2: Comparison of the "omega-3 index" (RBC EPA+DHA composition) in adult USA patients with acute coronary syndrome (ACS, $n=768$ ) [100], adult MDD patients residing in the USA or UK $(n=42)[102,105,106]$, healthy adults (HAs) residing in the U.S. $(n=163)$ [58], and healthy adults residing in Japan $(n=456)$ [57]. Proposed risk zones for sudden cardiac death (SCD) derived from prior prospective longitudinal evidence are indicated [99]. Note that MDD patients exhibit an "omega-3 index" that is similar to patients with ACS and places them at high risk for SCD.

those without current depression, and depression symptom severity was inversely correlated with plasma DHA composition [109]. In a third larger study, among ACS patients $(n=759)$, those with depression exhibited significantly lower RBC EPA+DHA composition relative to those without depression $(2.9 \pm 1.5 \%$ versus $3.3 \pm 1.8 \%, P=.002)$ [110]. Taken collectively, these data support an inverse relationship between $\mathrm{n}-3$ fatty acid status and depression in ACS patients.

\section{Biological Mechanisms}

There are several plausible biological mechanisms that could potentially link membrane n-3 fatty acid deficiency observed in MDD with increased risk for CHD. In addition to emerging clinical and preclinical evidence that n-3 fatty acids are protective against cardiac arrhythmias [111-114], other mechanisms including enhanced platelet reactivity and aggregation, elevated triglyceride levels, and inflammation, have received increasing experimental attention and are reviewed separately below. 
7.1. Platelet Aggregation. The antithrombotic actions of n3 fatty acids have been well documented [115], and platelet functional abnormalities, including increased platelet reactivity and aggregation associated with thromboembolic events, have been proposed as a potential mechanism by which depression increases risk for CHD [116, 117]. Blood platelets express serotonin $5-\mathrm{HT}_{2 \mathrm{~A}}$ receptors, and elevated 5$\mathrm{HT}_{2 \mathrm{~A}}$ receptor binding density has been observed in platelets, as well as postmortem prefrontal cortex, of depressed suicide victims [118-122]. Moreover, chronic dietary n-3 fatty acid insufficiency is associated with significant elevations in 5$\mathrm{HT}_{2 \mathrm{~A}}$ receptor binding density in the rat prefrontal cortex $[123,124]$. Platelet $5-\mathrm{HT}_{2 \mathrm{~A}}$ receptors are coupled to the phosphoinositide (PI) signal transduction pathway, and platelets obtained from MDD patients exhibit several indices consistent with PI-signaling hyperactivity, including elevated basal and/or stimulated intracellular inositol triphosphate, diacylglycerol, and/or calcium concentrations [125]. It is relevant, therefore, that previous preclinical studies have found that chronic EPA+DHA feeding significantly reduces indices of basal and stimulated PI signal transduction in platelets, neutrophils, and cardiac myocytes [126-129]. Moreover, $5-\mathrm{HT}_{2 \mathrm{~A}}$ receptors may also be coupled to phospholipase $\mathrm{A}_{2} \quad\left(\mathrm{PLA}_{2}\right)$ which liberates membrane acetylated arachidonic acid, a precursor for proinflammatory prostaglandin synthesis, and chronic dietary n-3 fatty acid deficiency is associated with significant elevations in $\mathrm{PLA}_{2}$ activity in the rat prefrontal cortex [130]. Together, these data suggest that elevated platelet $5-\mathrm{HT}_{2 \mathrm{~A}}$ receptor-mediated signaling secondary to n-3 fatty acid deficiency may increase risk of thromboembolic events in patients with MDD and CHD [131].

7.2. Inflammation. The mechanisms by which EPA+DHA reduce inflammatory signaling have been reviewed in detail previously [132] and include direct competition for cyclooxygenase-2- (COX-2) mediated arachidonic acid metabolism into proinflammatory prostaglandins and suppression of proinflammatory cytokine production. Several cross-sectional studies have observed an inverse correlation between blood EPA+DHA levels and markers of inflammation, including C-reactive protein (CRP) and proinflammatory cytokine interleukin-6 (IL-6) levels, among healthy adult men and women [133-136]. Inflammation is thought to be a key factor in the progression of atherosclerotic vascular disease, and elevations in the inflammatory marker CRP are associated with higher long-term risk for future CHD events [137]. Moreover, a cross-sectional study of 992 individuals with stable coronary artery disease found that RBC DHA+EPA levels were inversely and independently correlated with CRP and IL-6 levels [138], and a randomized controlled study found that chronic (91 d) DHA treatment significantly reduced CRP and IL-6 levels in hypertriglyceridemic men [139]. Cross-sectional surveys and case-control studies have also found elevated blood markers of inflammation, including CRP and IL-6, in patients with MDD relative to healthy controls, and that these markers were positively correlated with depression symptom severity [140-145]. Lastly, greater CRP levels have been observed in CHD outpatients with MDD compared with CHD outpatients without MDD [146]. However, it is notable that the Heart and Soul Study of 984 participants found that current MDD was associated with lower levels of inflammatory marker including CRP and IL-6 in both unadjusted and adjusted models [147].

7.3. Elevated Triglycerides. Elevated triglyceride levels (200$500 \mathrm{mg} / \mathrm{dL}$ ) have been found to be an independent, albeit modest, risk factor for CHD [148-150]. It has been known for over 20 years that the regular consumption of fish is associated with a $20 \%-40 \%$ reduction in plasma triglyceride levels [151], and n-3 fatty acids decrease hepatic triglyceride biosynthesis and hepatic clearance [152]. Several randomized controlled trials have consistently observed significant reductions in triglyceride levels $(\sim 25 \%)$ following daily $\mathrm{EPA}+\mathrm{DHA}(\sim 4 \mathrm{~g} / \mathrm{d})$ treatment relative to placebo in patients with hypertriglyceridemia $(\geq 500 \mathrm{mg} / \mathrm{dL})$ [153]. It is also notable that a study reported reduced depression symptom severity following resolution of severe hypertriglyceridemia $(\geq 500 \mathrm{mg} / \mathrm{dl}$ ) after treatment with gemfibrozil (Lopid) [154]. The American Heart Association currently recommends that patients with hypertriglyceridemia consume 2-4 g EPA+DHA per day [155], and in 2004 the U.S. Food and Drug Administration approved EPA+DHA ethyl esters (Omacor) for adjunctive treatment of hypertrigyceridemia. Moreover, two randomized controlled trials found that concomitant treatment with EPA [156] or EPA+DHA [157] significantly and dose-dependently decreased elevated triglyceride levels in schizophrenic patients treated with the atypical antipsychotic clozapine.

Surprisingly few studies have investigated fasting triglyceride levels in patients with MDD, and the existing results are mixed. For example, one small case-control study found that although fasting triglyceride levels in male and female MDD patients did not differ from healthy controls, triglyceride levels were greater in male patients with melancholic features compared with men with atypical features [158]. A second case-control study that did not segregate by MDD subtype did not observe significant differences in fasting triglyceride levels in MDD patients $(n=100)$ relative to healthy controls $(n=100)$ [159]. Moreover, a cross-sectional study of 3490 men aged 31-45 years did not observe elevated triglycerides in subjects diagnosed with MDD [160], and another study found that triglyceride levels were not associated with depression 1 month after an acute myocardial infarction [161]. However, a cross-sectional study found that in a sample of 5439 men aged $71-89$ years, $32 \%$ of subjects with depression had high fasting triglyceride levels compared with $21 \%$ of nondepressed subjects [162], and patients diagnosed with MDD after a recent ACS exhibited significantly higher fasting triglyceride levels relative to nondepressed ACS patients [108]. Although these findings do not unanimously support elevated triglyceride levels in MDD, recent studies have found a stronger association between nonfasting (postprandial state) triglyceride levels and cardiovascular risk compared to fasting triglyceride 
levels $[163,164]$. Moreover, elevated triglyceride levels ( $>150 \mathrm{mg} / \mathrm{dL}$ ) are observed in $25 \%-35 \%$ of the general U.S. population [165]. Future studies are therefore warranted to investigate whether patients with MDD exhibit elevated nonfasting triglyceride levels, and whether these levels are associated with n-3 fatty acid status and depression symptom severity.

\section{Conclusions and Hypothesis Evaluation}

There is now a substantial body of evidence linking n-3 fatty acid deficiency with both MDD and CHD. Support for the hypothesis that $\mathrm{n}-3$ fatty acid deficiency represents a preventable risk factor for comorbid $\mathrm{CHD}$ in $\mathrm{MDD}$ includes (1) cross-national and cross-sectional epidemiological surveys finding an inverse correlation between n-3 fatty acid status and prevalence rates of both CHD and MDD, (2) prospective studies finding that lower dietary or RBC $\mathrm{EPA}+\mathrm{DHA}$ levels increase risk for both MDD and CHD, (3) case-control studies finding that a large subset of MDD patients exhibit an RBC EPA+DHA level that places them at high risk for emergent CHD morbidity and mortality relative to the general population, (4) meta-analyses of randomized controlled secondary $\mathrm{n}-3$ fatty acid intervention studies finding significant advantage of n-3 fatty acids over placebo for secondary prevention of cardiac events in CHD patients and depression symptom severity in MDD patients, (5) cross-sectional and controlled intervention studies finding that $\mathrm{n}-3$ fatty acid status is inversely correlated with other documented CHD risk factors, including increased platelet reactivity and aggregation, augmented inflammatory signaling, and elevated fasting triglyceride levels, and (6) ACS patients diagnosed with MDD exhibit significantly lower plasma EPA+DHA levels compared with nondepressed ACS patients.

The most direct refutation of this hypothesis comes from a prospective longitudinal study finding that baseline $\mathrm{n}$ 3 fatty acid intake was inversely correlated with baseline depressive symptoms but was not associated with increased long-term CHD risk [85]. However, this study has several notable limitations. Firstly, this study did not account for potential changes in dietary $n-3$ fatty acid intake after baseline measurements were obtained, and it remains possible that subjects increased n-3 fatty acid intake postbaseline. Second, this study was conducted in a relatively small cohort $(n=332)$, and larger prospective trials have observed an inverse relationship between baseline n-3 fatty acid status and long-term CHD risk (reviewed above). Lastly, this study used a dietary n-3 fatty acid questionnaire to define baseline $\mathrm{n}-3$ fatty acid status, and no objective measures (i.e., $\mathrm{RBC}$ EPA+DHA composition) were collected to corroborate accuracy.

In view of the weight of current evidence, additional studies are clearly warranted to directly evaluate the interrelationship between $\mathrm{n}-3$ fatty acid deficiency and CHD comorbidity in MDD. A definitive test of the proposed hypothesis would be to determine in a prospective longitudinal controlled trial whether increasing the n-3 fatty acid status of MDD patients decreases indices of CHD risk and emergent cardiac events and mortality. Increasing RBC EPA+DHA composition to $\geq 8 \%$, which is associated with the greatest protection from CHD mortality [99], would represent an appropriate target, and a prior study demonstrated that RBC DHA+EPA composition of $7.8 \%$ was achievable after 8-week treatment with DHA $(864 \mathrm{mg} / \mathrm{d})$ $+\operatorname{EPA}(1,296 \mathrm{mg} / \mathrm{d})(\sim 2.0 \mathrm{~g} / \mathrm{d})$ in adult male and female subjects [166]. Older MDD patients at greater risk for CHD mortality at study entry (i.e., RBC EPA+DHA $\geq 4.0 \%$ ) would represent an appropriate cohort. Based on the evidence reviewed here, it is predicted that increasing n-3 fatty acid status of MDD patients to $\geq 8 \%$ would be associated with a significant reduction in CHD risk factors, including depression symptom severity, nonfasting triglyceride levels, indices of platelet aggregation, CRP and IL-6 levels, and ultimately reduced risk for emergent cardiac events and SCD.

\section{References}

[1] C. J. L. Murray and A. D. Lopez, "Global mortality, disability, and the contribution of risk factors: global burden of disease study," The Lancet, vol. 349, no. 9063, pp. 1436-1442, 1997.

[2] L. Andrade, J. J. Caraveo-Anduaga, P. Berglund, et al., "Crossnational comparisons of the prevalences and correlates of mental disorders. WHO International Consortium in Psychiatric Epidemiology," Bulletin of the World Health Organization, vol. 78, no. 4, pp. 413-426, 2000.

[3] F. Angst, H. H Stassen, P. J Clayton, and J. Angst, "Mortality of patients with mood disorders: follow-up over 34-38 years," Journal of Affective Disorders, vol. 68, no. 2-3, pp. 167-181, 2002.

[4] K. Goldston and A. J. Baillie, "Depression and coronary heart disease: a review of the epidemiological evidence, explanatory mechanisms and management approaches," Clinical Psychology Review, vol. 28, no. 2, pp. 288-306, 2008.

[5] D. L. Musselman, D. L. Evans, and C. B. Nemeroff, "The relationship of depression to cardiovascular disease: epidemiology, biology, and treatment," Archives of General Psychiatry, vol. 55, no. 7, pp. 580-592, 1998.

[6] C. B. Nemeroff, D. L. Musselman, and D. L. Evans, "Depression and cardiac disease," Depression and Anxiety, vol. 8, supplement 1, pp. 71-79, 1998.

[7] B. Rudisch and C. B. Nemeroff, "Epidemiology of comorbid coronary artery disease and depression," Biological Psychiatry, vol. 54, no. 3, pp. 227-240, 2003.

[8] K. Van der Kooy, H. van Hout, H. Marwijk, H. Marten, C. Stehouwer, and A. Beekman, "Depression and the risk for cardiovascular diseases: systematic review and meta analysis," International Journal of Geriatric Psychiatry, vol. 22, no. 7, pp. 613-626, 2007.

[9] L. R. Wulsin and B. M. Singal, "Do depressive symptoms increase the risk for the onset of coronary disease? A systematic quantitative review," Psychosomatic Medicine, vol. 65, no. 2, pp. 201-210, 2003.

[10] M. A. Ehringer, S. H. Rhee, S. Young, R. Corley, and J. K. Hewitt, "Genetic and environmental contributions to common psychopathologies of childhood and adolescence: a study of twins and their siblings," Journal of Abnormal Child Psychology, vol. 34, no. 1, pp. 1-17, 2006. 
[11] K. R. Merikangas, A. Chakravarti, S. O. Moldin, et al., "Future of genetics of mood disorders research," Biological Psychiatry, vol. 52, no. 6, pp. 457-477, 2002.

[12] P. F. Sullivan, M. C. Neale, and K. S. Kendler, "Genetic epidemiology of major depression: review and meta-analysis," American Journal of Psychiatry, vol. 157, no. 10, pp. 15521562, 2000.

[13] M. A. Austin, M.-C. King, R. D. Bawol, S. B. Hulley, and G. D. Friedman, "Risk factors for coronary heart disease in adult female twins. Genetic heritability and shared environmental influences," American Journal of Epidemiology, vol. 125, no. 2, pp. 308-318, 1987.

[14] A. Evans, G. C. M. Van Baal, P. McCarron, et al., "The genetics of coronary heart disease: the contribution of twin studies," Twin Research, vol. 6, no. 5, pp. 432-441, 2003.

[15] M. E. Marenberg, N. Risch, L. F. Berkman, B. Floderus, and U. de Faire, "Genetic susceptibility to death from coronary heart disease in a study of twins," The New England Journal of Medicine, vol. 330, no. 15, pp. 1041-1046, 1994.

[16] S. Zdravkovic, A. Wienke, N. L. Pedersen, M. E. Marenberg, A. I. Yashin, and U. de Faire, "Heritability of death from coronary heart disease: a 36-year follow-up of 20966 Swedish twins," Journal of Internal Medicine, vol. 252, no. 3, pp. 247254, 2002.

[17] M. A. Whooley, "Depression and cardiovascular disease: healing the broken-hearted," Journal of the American Medical Association, vol. 295, no. 24, pp. 2874-2881, 2006.

[18] W. S. Harris, "The omega-3 index as a risk factor for coronary heart disease," American Journal of Clinical Nutrition, vol. 87, no. 6, pp. 1997S-2002S, 2008.

[19] R. K. McNamara, "Evidence-based evaluation of omega-3 fatty acid deficiency as a risk factor for recurrent neuropsychiatric illness: current status and future directions," in Fish Oils and Health, E. P. Heikkinen, Ed., pp. 7-67, Nova Science, New York, NY, USA, 2008.

[20] M. P. Freeman, J. R. Hibbeln, K. L. Wisner, et al., “Omega-3 fatty acids: evidence basis for treatment and future research in psychiatry," Journal of Clinical Psychiatry, vol. 67, no. 12, pp. 1954-1967, 2006.

[21] P. M. Kris-Etherton, W. S. Harris, and L. J. Appel, "Omega3 fatty acids and cardiovascular disease: new recommendations from the American Heart Association," Arteriosclerosis, Thrombosis, and Vascular Biology, vol. 23, no. 2, pp. 151-152, 2003.

[22] D. F. Horrobin and C. N. Bennett, "Depression and bipolar disorder: relationships to impaired fatty acid and phospholipid metabolism and to diabetes, cardiovascular disease, immunological abnormalities, cancer, ageing and osteoporosis. Possible candidate genes," Prostaglandins Leukotrienes and Essential Fatty Acids, vol. 60, no. 4, pp. 217-234, 1999.

[23] W. E. Severus, A. B. Littman, and A. L. Stoll, "Omega-3 fatty acids, homocysteine, and the increased risk of cardiovascular mortality in major depressive disorder," Harvard Review of Psychiatry, vol. 9, no. 6, pp. 280-293, 2001.

[24] K. C. Burke, J. D. Burke Jr., D. S. Rae, and D. A. Regier, "Comparing age at onset of major depression and other psychiatric disorders by birth cohorts in five US community populations," Archives of General Psychiatry, vol. 48, no. 9, pp. 789-795, 1991.

[25] K. N. R. Chengappa, D. J. Kupfer, E. Frank, et al., "Relationship of birth cohort and early age at onset of illness in a bipolar disorder case registry," American Journal of Psychiatry, vol. 160, no. 9, pp. 1636-1642, 2003.
[26] S. S. Chugh, K. Reinier, C. Teodorescu, et al., "Epidemiology of sudden cardiac death: clinical and research implications," Progress in Cardiovascular Diseases, vol. 51, no. 3, pp. 213228, 2008.

[27] H. Ito, R. Kawashima, S. Awata, et al., "Hypoperfusion in the limbic system and prefrontal cortex in depression: SPECT with anatomic standardization technique," Journal of Nuclear Medicine, vol. 37, no. 3, pp. 410-414, 1996.

[28] Y. Kohn, N. Freedman, H. Lester, et al., "99mTc-HMPAO SPECT study of cerebral perfusion after treatment with medication and electroconvulsive therapy in major depression," Journal of Nuclear Medicine, vol. 48, no. 8, pp. 1273-1278, 2007.

[29] M. Y. Abeywardena and R. J. Head, "Longchain n-3 polyunsaturated fatty acids and blood vessel function," Cardiovascular Research, vol. 52, no. 3, pp. 361-371, 2001.

[30] E. F. Ellis, R. J. Police, L. M. Yancey, M. N. Grabeel, M. L. Heizer, and S. A. Holt, "Effect of fish oil n-3 fatty acids on cerebral microcirculation," American Journal of Physiology, vol. 258, no. 6, pp. H1780-H1785, 1990.

[31] K. Matsuo, Y. Onodera, T. Hamamoto, K. Muraki, N. Kato, and T. Kato, "Hypofrontality and microvascular dysregulation in remitted late-onset depression assessed by functional near-infrared spectroscopy," NeuroImage, vol. 26, no. 1, pp. 234-242, 2005.

[32] A. E. Leonard, S. L. Pereira, H. Sprecher, and Y.-S. Huang, "Elongation of long-chain fatty acids," Progress in Lipid Research, vol. 43, no. 1, pp. 36-54, 2004.

[33] M. T. Nakamura and T. Y. Nara, "Structure, function, and dietary regulation of $\Delta 6, \Delta 5$, and $\Delta 9$ desaturases," Annual Review of Nutrition, vol. 24, pp. 345-376, 2004.

[34] H. Sprecher and Q. Chen, "Polyunsaturated fatty acid biosynthesis: a microsomal-peroxisomal process," Prostaglandins Leukotrienes and Essential Fatty Acids, vol. 60, no. 5-6, pp. 317-321, 1999.

[35] H. P. Cho, M. Nakamura, and S. D. Clarke, "Cloning, expression, and fatty acid regulation of the human $\Delta-5$ desaturase," The Journal of Biological Chemistry, vol. 274, no. 52, pp. 37335-37339, 1999.

[36] H. P. Cho, M. T. Nakamura, and S. D. Clarke, "Cloning, expression, and nutritional regulation of the mammalian $\Delta-6$ desaturase," The Journal of Biological Chemistry, vol. 274, no. 1, pp. 471-477, 1999.

[37] A. Marquardt, H. Stöhr, K. White, and B. H. F. Weber, “cDNA cloning, genomic structure, and chromosomal localization of three members of the human fatty acid desaturase family," Genomics, vol. 66, no. 2, pp. 175-183, 2000.

[38] R. K. McNamara, Y. Liu, R. Jandacek, T. Rider, and P. Tso, "The aging human orbitofrontal cortex: decreasing polyunsaturated fatty acid composition and associated increases in lipogenic gene expression and stearoyl-CoA desaturase activity," Prostaglandins Leukotrienes and Essential Fatty Acids, vol. 78, no. 4-5, pp. 293-304, 2008.

[39] M. Igarashi, K. Ma, L. Chang, J. M. Bell, and S. I. Rapoport, "Dietary n-3 PUFA deprivation for 15 weeks upregulates elongase and desaturase expression in rat liver but not brain," Journal of Lipid Research, vol. 48, no. 11, pp. 2463-2470, 2007.

[40] C. E. Childs, M. Romeu-Nadal, G. C. Burdge, and P. C. Calder, "Gender differences in the n-3 fatty acid content of tissues," Proceedings of the Nutrition Society, vol. 67, no. 1, pp. 19-27, 2008. 
[41] E. J. Giltay, L. J. G. Gooren, A. W. F. T. Toorians, M. B. Katan, and P. L. Zock, "Docosahexaenoic acid concentrations are higher in women than in men because of estrogenic effects," American Journal of Clinical Nutrition, vol. 80, no. 5, pp. 1167-1174, 2004.

[42] R. K. McNamara, J. Able, R. Jandacek, T. Rider, and P. Tso, "Gender differences in rat erythrocyte and brain docosahexaenoic acid composition: role of ovarian hormones and dietary omega-3 fatty acid composition," Psychoneuroendocrinology, vol. 34, no. 4, pp. 532-539, 2009.

[43] R. R. Brenner, "Hormonal modulation of delta6 and delta5 desaturases: case of diabetes," Prostaglandins Leukotrienes and Essential Fatty Acids, vol. 68, no. 2, pp. 151-162, 2003.

[44] M. A. Contreras and S. I. Rapoport, "Recent studies on interactions between n-3 and n-6 polyunsaturated fatty acids in brain and other tissues," Current Opinion in Lipidology, vol. 13, no. 3, pp. 267-272, 2002.

[45] R. K. McNamara and S. E. Carlson, "Role of omega3 fatty acids in brain development and function: potential implications for the pathogenesis and prevention of psychopathology," Prostaglandins Leukotrienes and Essential Fatty Acids, vol. 75, no. 4-5, pp. 329-349, 2006.

[46] C. A. Francois, S. L. Connor, L. C. Bolewicz, and W. E. Connor, "Supplementing lactating women with flaxseed oil does not increase docosahexaenoic acid in their milk," The American Journal of Clinical Nutrition, vol. 77, no. 1, pp. 226233, 2003.

[47] H. Gerster, "Can adults adequately convert $\alpha$-linolenic acid (18:3n-3) to eicosapentaenoic acid (20:5n-3) and docosahexaenoic acid (22:6n-3)?" International Journal for Vitamin and Nutrition Research, vol. 68, no. 3, pp. 159-173, 1998.

[48] R. J. Pawlosky, J. R. Hibbeln, J. A. Novotny, and N. Salem Jr., "Physiological compartmental analysis of $\alpha$-linolenic acid metabolism in adult humans," Journal of Lipid Research, vol. 42, no. 8, pp. 1257-1265, 2001.

[49] G. C. Burdge and P. C. Calder, "Conversion of $\alpha$-linolenic acid to longer-chain polyunsaturated fatty acids in human adults," Reproduction Nutrition Development, vol. 45, no. 5, pp. 581-597, 2005.

[50] J. R. Hibbeln, L. R. G. Nieminen, T. L. Blasbalg, J. A. Riggs, and W. E. M. Lands, "Healthy intakes of n-3 and n-6 fatty acids: etimations considering worldwide diversity," American Journal of Clinical Nutrition, vol. 83, no. 6, pp. 1483S-1493S, 2006.

[51] G. Malerba, L. Schaeffer, L. Xumerle, et al., "SNPs of the FADS gene cluster are associated with polyunsaturated fatty acids in a cohort of patients with cardiovascular disease," Lipids, vol. 43, no. 4, pp. 289-299, 2008.

[52] P. Rzehak, J. Heinrich, N. Klopp, et al., "Evidence for an association between genetic variants of the fatty acid desaturase 1 fatty acid desaturase 2 (FADS1 FADS2) gene cluster and the fatty acid composition of erythrocyte membranes," British Journal of Nutrition, vol. 101, no. 1, pp. 20-26, 2009.

[53] L. Schaeffer, H. Gohlke, M. Müller, et al., "Common genetic variants of the FADS1 FADS2 gene cluster and their reconstructed haplotypes are associated with the fatty acid composition in phospholipids," Human Molecular Genetics, vol. 15, no. 11, pp. 1745-1756, 2006.

[54] L. Xie and S. M. Innis, "Genetic variants of the FADS1 FADS2 gene cluster are associated with altered (n-6) and (n-3) essential fatty acids in plasma and erythrocyte phospholipids in women during pregnancy and in breast milk during lactation," Journal of Nutrition, vol. 138, no. 11, pp. 22222228, 2008.
[55] N. Martinelli, D. Girelli, G. Malerba, et al., "FADS genotypes and desaturase activity estimated by the ratio of arachidonic acid to linoleic acid are associated with inflammation and coronary artery disease," American Journal of Clinical Nutrition, vol. 88, no. 4, pp. 941-949, 2008.

[56] World Health Organization, World Health Organization, "Fish and Fishery Products: World Apparent Consumption Based On Food Balance Sheets (1961-1993)," FAO Fisheries Circular, no. 821 Rev. 3, Food and Agriculture Organization, Rome (1996).

[57] M. Itomura, S. Fujioka, K. Hamazaki, et al., "Factors influencing EPA+ DHA levels in red blood cells in Japan," In Vivo, vol. 22, no. 1, pp. 131-136, 2008.

[58] S. A. Sands, K. J. Reid, S. L. Windsor, and W. S. Harris, “The impact of age, body mass index, and fish intake on the EPA and DHA content of human erythrocytes," Lipids, vol. 40, no. 4, pp. 343-347, 2005.

[59] L. Andrade, J. J. Caraveo-Anduaga, P. Berglund, et al., "The epidemiology of major depressive episodes: results from the International Consortium of Psychiatric Epidemiology (ICPE) Surveys," International Journal of Methods in Psychiatric Research, vol. 12, no. 1, pp. 3-21, 2003.

[60] N. Kawakami, H. Shimizu, T. Haratani, N. Iwata, and T. Kitamura, "Lifetime and 6-month prevalence of DSM-IIIR psychiatric disorders in an urban community in Japan," Psychiatry Research, vol. 121, no. 3, pp. 293-301, 2004.

[61] R. C. Kessler, K. R. Merikangas, and P. S. Wang, "Prevalence, comorbidity, and service utilization for mood disorders in the United States at the beginning of the twenty-first century," Annual Review of Clinical Psychology, vol. 3, pp. 137-158, 2007.

[62] World Health Organization, World Health Statistics Annuals, 1985-1995, WHO, Geneva, Switzerland, 1986-1996.

[63] J. R. Hibbeln, "Fish consumption and major depression," The Lancet, vol. 351, no. 9110, p. 1213, 1998.

[64] M. Peet, "International variations in the outcome of schizophrenia and the prevalence of depression in relation to national dietary practices: an ecological analysis," British Journal of Psychiatry, vol. 184, pp. 404-408, 2004.

[65] S. Noaghiul and J. R. Hibbeln, "Cross-national comparisons of seafood consumption and rates of bipolar disorders," American Journal of Psychiatry, vol. 160, no. 12, pp. 22222227, 2003.

[66] J. R. Hibbeln, "Seafood consumption, the DHA content of mothers' milk and prevalence rates of postpartum depression: a cross-national, ecological analysis," Journal of Affective Disorders, vol. 69, no. 1-3, pp. 15-29, 2002.

[67] K. M. Appleton, T. J. Peters, R. C. Hayward, et al., "Depressed mood and n-3 polyunsaturated fatty acid intake from fish: non-linear or confounded association?" Social Psychiatry and Psychiatric Epidemiology, vol. 42, no. 2, pp. 100-104, 2007.

[68] K. M. Appleton, J. V. Woodside, J. W. Yarnell, et al., "Depressed mood and dietary fish intake: direct relationship or indirect relationship as a result of diet and lifestyle?" Journal of Affective Disorders, vol. 104, no. 1-3, pp. 217-223, 2007.

[69] R. Hakkarainen, T. Partonen, J. Haukka, J. Virtamo, D. Albanes, and J. Lönnqvist, "Is low dietary intake of omega3 fatty acids associated with depression?" American Journal of Psychiatry, vol. 161, no. 3, pp. 567-569, 2004.

[70] M. B. Raeder, V. M. Steen, S. E. Vollset, and I. Bjelland, "Associations between cod liver oil use and symptoms of depression: the Hordaland Health Study," Journal of Affective Disorders, vol. 101, no. 1-3, pp. 245-249, 2007. 
[71] A. Tanskanen, J. R. Hibbeln, J. Tuomilehto, et al., "Fish consumption and depressive symptoms in the general population in Finland," Psychiatric Services, vol. 52, no. 4, pp. 529531, 2001.

[72] M. Timonen, D. Horrobin, J. Jokelainen, J. Laitinen, A. Herva, and P. Räsänen, "Fish consumption and depression: the Northern Finland 1966 birth cohort study," Journal of Affective Disorders, vol. 82, no. 3, pp. 447-452, 2004.

[73] H. Iso, M. Kobayashi, J. Ishihara, et al., "Intake of fish and n3 fatty acids and risk of coronary heart disease among Japanese: the Japan Public Health Center-Based (JPHC) study cohort I," Circulation, vol. 113, no. 2, pp. 195-202, 2006.

[74] D. B. Panagiotakos, C. Pitsavos, A. Zampelas, et al., "Fish consumption and the risk of developing acute coronary syndromes: the CARDIO2000 study," International Journal of Cardiology, vol. 102, no. 3, pp. 403-409, 2005.

[75] N. K. McGrath-Hanna, D. M. Greene, R. J. Tavernier, and A. Bult-Ito, "Diet and mental health in the Arctic: is diet an important risk factor for mental health in circumpolar peoples? A review," International Journal of Circumpolar Health, vol. 62, no. 3, pp. 228-241, 2003.

[76] L. A. Colangelo, K. He, M. A. Whooley, M. L. Daviglus, and K. Liu, "Higher dietary intake of long-chain omega3 polyunsaturated fatty acids is inversely associated with depressive symptoms in women," Nutrition, vol. 25, no. 10, pp. 1011-1019, 2009.

[77] A.-M. Rees, M.-P. Austin, C. Owen, and G. Parker, “Omega-3 deficiency associated with perinatal depression: case control study," Psychiatry Research, vol. 166, no. 2-3, pp. 254-259, 2009.

[78] J. Golding, C. Steer, P. Emmett, J. M. Davis, and J. R. Hibbeln, "High levels of depressive symptoms in pregnancy with low omega-3 fatty acid intake from fish," Epidemiology, vol. 20, no. 4, pp. 598-603, 2009.

[79] S. J. Otto, R. H. M. de Groot, and G. Hornstra, "Increased risk of postpartum depressive symptoms is associated with slower normalization after pregnancy of the functional docosahexaenoic acid status," Prostaglandins Leukotrienes and Essential Fatty Acids, vol. 69, no. 4, pp. 237-243, 2003.

[80] C. M. Albert, H. Campos, M. J. Stampfer, et al., "Blood levels of long-chain n-3 fatty acids and the risk of sudden death," The New England Journal of Medicine, vol. 346, no. 15, pp. 1113-1118, 2002.

[81] D. S. Siscovick, T. E. Raghunathan, I. King, et al., "Dietary intake and cell membrane levels of long-chain n-3 polyunsaturated fatty acids and the risk of primary cardiac arrest," Journal of the American Medical Association, vol. 274, no. 17, pp. 1363-1367, 1995.

[82] W. S. Harris, K. J. Reid, S. A. Sands, and J. A. Spertus, "Blood omega- 3 and trans fatty acids in middle-aged acute coronary syndrome patients," American Journal of Cardiology, vol. 99, no. 2, pp. 154-158, 2007.

[83] F. B. Hu, L. Bronner, W. C. Willett, et al., "Fish and omega3 fatty acid intake and risk of coronary heart disease in women," Journal of the American Medical Association, vol. 287, no. 14, pp. 1815-1821, 2002.

[84] K. He, Y. Song, M. L. Daviglus, et al., "Accumulated evidence on fish consumption and coronary heart disease mortality: a meta-analysis of cohort studies," Circulation, vol. 109, no. 22, pp. 2705-2711, 2004.

[85] M. H. Kamphuis, M. I. Geerlings, M. A. R. Tijhuis, S. Kalmijn, D. E. Grobbee, and D. Kromhout, "Depression and cardiovascular mortality: a role for $\mathrm{n}-3$ fatty acids?" American Journal of Clinical Nutrition, vol. 84, no. 6, pp. 1513-1517, 2006.

[86] K. M. Appleton, R. C. Hayward, D. Gunnell, et al., "Effects of n-3 long-chain polyunsaturated fatty acids on depressed mood: systematic review of published trials," American Journal of Clinical Nutrition, vol. 84, no. 6, pp. 1308-1316, 2006.

[87] P.-Y. Lin and K.-P. Su, "A meta-analytic review of doubleblind, placebo-controlled trials of antidepressant efficacy of omega-3 fatty acids," Journal of Clinical Psychiatry, vol. 68, no. 7, pp. 1056-1061, 2007.

[88] R. K. McNamara, "Evaluation of docosahexaenoic acid deficiency as a preventable risk factor for recurrent affective disorders: current status, future directions, and dietary recommendations," Prostaglandins, Leukotrienes and Essential Fatty Acids, vol. 81, no. 2-3, pp. 223-231, 2009.

[89] G. Parker, N. A. Gibson, H. Brotchie, G. Heruc, A.-M. Rees, and D. Hadzi-Pavlovic, "Omega-3 fatty acids and mood disorders," American Journal of Psychiatry, vol. 163, no. 6, pp. 969-978, 2006.

[90] B. M. Ross, J. Seguin, and L. E. Sieswerda, "Omega-3 fatty acids as treatments for mental illness: which disorder and which fatty acid?" Lipids in Health and Disease, vol. 6, article $21,2007$.

[91] H. Nemets, B. Nemets, A. Apter, Z. Bracha, and R. H. Belmaker, "Omega-3 treatment of childhood depression: a controlled, double-blind pilot study," American Journal of Psychiatry, vol. 163, no. 6, pp. 1098-1100, 2006.

[92] H. C. Bucher, P. Hengstler, C. Schindler, and G. Meier, "N-3 polyunsaturated fatty acids in coronary heart disease: a metaanalysis of randomized controlled trials," American Journal of Medicine, vol. 112, no. 4, pp. 298-304, 2002.

[93] Y. T. Zhao, Q. Chen, Y. X. Sun, et al., "Prevention of sudden cardiac death with omega-3 fatty acids in patients with coronary heart disease: a meta-analysis of randomized controlled trials," Annals of Medicine, vol. 41, no. 4, pp. 301310, 2009.

[94] M. Yokoyama, H. Origasa, M. Matsuzaki, et al., "Effects of eicosapentaenoic acid on major coronary events in hypercholesterolaemic patients (JELIS): a randomised openlabel, blinded endpoint analysis," The Lancet, vol. 369, no. 9567, pp. 1090-1098, 2007.

[95] Q. Sun, J. Ma, H. Campos, S. E. Hankinson, and F. B. Hu, "Comparison between plasma and erythrocyte fatty acid content as biomarkers of fatty acid intake in US women," American Journal of Clinical Nutrition, vol. 86, no. 1, pp. 7481, 2007.

[96] H. M. Vidgren, J. J. Agren, U. Schwab, T. Rissanen, O. Hänninen, and M. I. J. Uusitupa, "Incorporation of n-3 fatty acids into plasma lipid fractions, and erythrocyte membranes and platelets during dietary supplementation with fish, fish oil, and docosahexaenoic acid-rich oil among healthy young men," Lipids, vol. 32, no. 7, pp. 697-705, 1997.

[97] W. S. Harris, S. A. Sands, S. L. Windsor, et al., "Omega3 fatty acids in cardiac biopsies from heart transplantation patients: correlation with erythrocytes and response to supplementation," Circulation, vol. 110, no. 12, pp. 16451649, 2004.

[98] W. E. Connor, M. Neuringer, and D. S. Lin, "Dietary effects on brain fatty acid composition: the reversibility of $n-3$ fatty acid deficiency and turnover of docosahexaenoic acid in the brain, erythrocytes, and plasma of rhesus monkeys," Journal of Lipid Research, vol. 31, no. 2, pp. 237-247, 1990. 
[99] W. S. Harris and C. Von Schacky, "The omega-3 index: a new risk factor for death from coronary heart disease?" Preventive Medicine, vol. 39, no. 1, pp. 212-220, 2004.

[100] R. C. Block, W. S. Harris, K. J. Reid, S. A. Sands, and J. A. Spertus, "EPA and DHA in blood cell membranes from acute coronary syndrome patients and controls," Atherosclerosis, vol. 197, no. 2, pp. 821-828, 2008.

[101] W. S. Harris, W. C. Poston, and C. K. Haddock, "Tissue n-3 and n- 6 fatty acids and risk for coronary heart disease events," Atherosclerosis, vol. 193, no. 1, pp. 1-10, 2007.

[102] R. Edwards, M. Peet, J. Shay, and D. Horrobin, "Omega-3 polyunsaturated fatty acid levels in the diet and in red blood cell membranes of depressed patients," Journal of Affective Disorders, vol. 48, no. 2-3, pp. 149-155, 1998.

[103] M. Maes, R. Smith, A. Christophe, P. Cosyns, R. Desnyder, and H. Meltzer, "Fatty acid composition in major depression: decreased $\omega 3$ fractions in cholesteryl esters and increased

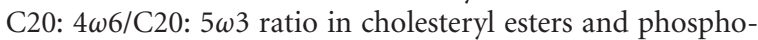
lipids," Journal of Affective Disorders, vol. 38, no. 1, pp. 35-46, 1996.

[104] M. Maes, A. Christophe, J. Delanghe, C. Altamura, H. Neels, and H. Y. Meltzer, "Lowered $\omega 3$ polyunsaturated fatty acids in serum phospholipids and cholesteryl esters of depressed patients," Psychiatry Research, vol. 85, no. 3, pp. 275-291, 1999.

[105] R. K. McNamara, R. Jandacek, T. Rider, P. Tso, Y. Dwivedi, and G. N. Pandey, "Selective erythrocyte omega-3 fatty acid deficits in adult patients with bipolar disorder: comparison with major depressive disorder," Biological Psychiatry, vol. 65, p. S140, 2009.

[106] M. Peet, B. Murphy, J. Shay, and D. Horrobin, "Depletion of omega-3 fatty acid levels in red blood cell membranes of depressive patients," Biological Psychiatry, vol. 43, no. 5, pp. 315-319, 1998.

[107] H. Tiemeier, H. R. van Tuijl, A. Hofman, A. J. Kiliaan, and M. M. B. Breteler, "Plasma fatty acid composition and depression are associated in the elderly: the Rotterdam Study," American Journal of Clinical Nutrition, vol. 78, no. 1, pp. 40-46, 2003.

[108] N. Frasure-Smith, F. Lespérance, and P. Julien, "Major depression is associated with lower omega-3 fatty acid levels in patients with recent acute coronary syndromes," Biological Psychiatry, vol. 55, no. 9, pp. 891-896, 2004.

[109] G. B. Parker, G. A. Heruc, T. M. Hilton, et al., "Low levels of docosahexaenoic acid identified in acute coronary syndrome patients with depression," Psychiatry Research, vol. 141, no. 3, pp. 279-286, 2006.

[110] A. A. Amin, R. A. Menon, K. J. Reid, W. S. Harris, and J. A. Spertus, "Acute coronary syndrome patients with depression have low blood cell membrane omega-3 fatty acid levels," Psychosomatic Medicine, vol. 70, no. 8, pp. 856-862, 2008.

[111] G. E. Billman, J. X. Kang, and A. Leaf, "Prevention of sudden cardiac death by dietary pure $\omega-3$ polyunsaturated fatty acids in dogs," Circulation, vol. 99, no. 18, pp. 2452-2457, 1999.

[112] A. Leaf, J. X. Kang, Y.-F. Xiao, and G. E. Billman, “Dietary n-3 fatty acids in the prevention of cardiac arrhythmias," Current Opinion in Clinical Nutrition and Metabolic Care, vol. 1, no. 2, pp. 225-228, 1998.

[113] D. M. Ninio, K. J. Murphy, P. R. Howe, and D. A. Saint, "Dietary fish oil protects against stretch-induced vulnerability to atrial fibrillation in a rabbit model," Journal of Cardiovascular Electrophysiology, vol. 16, no. 11, pp. 11891194, 2005.
[114] C. von Schacky, "Omega-3 fatty acids: antiarrhythmic, proarrhythmic or both?" Current Opinion in Clinical Nutrition and Metabolic Care, vol. 11, no. 2, pp. 94-99, 2008.

[115] K. Vanschoonbeek, M. A. H. Feijge, M. Paquay, et al., "Variable hypocoagulant effect of fish oil intake in humans: modulation of fibrinogen level and thrombin generation," Arteriosclerosis, Thrombosis, and Vascular Biology, vol. 24, no. 9, pp. 1734-1740, 2004.

[116] C. B. Nemeroff and D. L. Musselman, "Are platelets the link between depression and ischemic heart disease?" American Heart Journal, vol. 140, supplement 4, pp. S57-S62, 2000.

[117] R. C. Ziegelstein, K. Parakh, A. Sakhuja, and U. Bhat, "Platelet function in patients with major depression," Internal Medicine Journal, vol. 39, no. 1, pp. 38-43, 2009.

[118] V. Arango, P. Ernsberger, P. M. Marzuk, et al., "Autoradiographic demonstration of increased serotonin 5-HT2 and $\beta$-adrenergic receptor binding sites in the brain of suicide victims," Archives of General Psychiatry, vol. 47, no. 11, pp. 1038-1047, 1990.

[119] J. J. Mann, M. Stanley, P. A. McBride, and B. S. McEwen, "Increased serotonin 2 and $\beta$-adrenergic receptor binding in the frontal cortices of suicide victims," Archives of General Psychiatry, vol. 43, no. 10, pp. 954-959, 1986.

[120] G. N. Pandey, Y. Dwivedi, H. S. Rizavi, et al., "Higher expression of serotonin 5-HT2A receptors in the postmortem brains of teenage suicide victims," American Journal of Psychiatry, vol. 159, no. 3, pp. 419-429, 2002.

[121] G. N. Pandey, S. C. Pandey, Y. Dwivedi, R. P. Sharma, P. G. Janicak, and J. M. Davis, "Platelet serotonin-2A receptors: a potential biological marker for suicidal behavior," American Journal of Psychiatry, vol. 152, no. 6, pp. 850-855, 1995.

[122] M. Stanley and J. J. Mann, "Increased serotonin-2 binding sites in frontal cortex of suicide victims," The Lancet, vol. 1, no. 8318 , pp. 214-216, 1983.

[123] S. Delion, S. Chalon, D. Guilloteau, J.-C. Besnard, and G. Durand, " $\alpha$-linolenic acid dietary deficiency alters agerelated changes of dopaminergic and serotoninergic neurotransmission in the rat frontal cortex," Journal of Neurochemistry, vol. 66, no. 4, pp. 1582-1591, 1996.

[124] R. K. McNamara, N. M. Richtand, and B. Levant, "Omega-3 fatty acid deficiency decreases dopamine $\mathrm{D}_{2}$ receptor binding and increases serotonin $5-\mathrm{HT}_{2 \mathrm{~A}}$ receptor binding in the adult rat prefrontal cortex," Biological Psychiatry, vol. 59, p. S146, 2006.

[125] R. K. McNamara, M. Ostrander, W. Abplanalp, N. M. Richtand, S. C. Benoit, and D. J. Clegg, "Modulation of phosphoinositide-protein kinase $\mathrm{C}$ signal transduction by omega-3 fatty acids: implications for the pathophysiology and treatment of recurrent neuropsychiatric illness," Prostaglandins Leukotrienes and Essential Fatty Acids, vol. 75, no. 4-5, pp. 237-257, 2006.

[126] A. Leaf, "Omega-3 fatty acids and prevention of ventricular fibrillation," Prostaglandins Leukotrienes and Essential Fatty Acids, vol. 52, no. 2-3, pp. 197-198, 1995.

[127] L. Medini, S. Colli, C. Mosconi, E. Tremoli, and C. Galli, "Diets rich in n-9, n-6 and n-3 fatty acids differentially affect the generation of inositol phosphates and of thromboxane by stimulated platelets, in the rabbit," Biochemical Pharmacology, vol. 39, no. 1, pp. 129-133, 1990.

[128] S. S. D. Nair, J. Leitch, and M. L. Garg, "Suppression of inositol phosphate release by cardiac myocytes isolated from fish oil-fed pigs," Molecular and Cellular Biochemistry, vol. 215, no. 1-2, pp. 57-64, 2000. 
[129] R. I. Sperling, A. I. Benincaso, C. T. Knoell, J. K. Larkin, K. F. Austen, and D. R. Robinson, "Dietary $\omega-3$ polyunsaturated fatty acids inhibit phosphoinositide formation and chemotaxis in neutrophils," The Journal of Clinical Investigation, vol. 91, no. 2, pp. 651-660, 1993.

[130] J. S. Rao, R. N. Ertley, J. C. DeMar Jr., S. I. Rapoport, R. P. Bazinet, and H.-J. Lee, "Dietary n-3 PUFA deprivation alters expression of enzymes of the arachidonic and docosahexaenoic acid cascades in rat frontal cortex," Molecular Psychiatry, vol. 12, no. 2, pp. 151-157, 2007.

[131] A. Schins, A. Honig, H. Crijns, L. Baur, and K. Hamulyák, "Increased coronary events in depressed cardiovascular patients: 5-HT 2A receptor as missing link?” Psychosomatic Medicine, vol. 65, no. 5, pp. 729-737, 2003.

[132] P. C. Calder, " $n-3$ polyunsaturated fatty acids and inflammation: from molecular biology to the clinic," Lipids, vol. 38, no. 4, pp. 343-352, 2003.

[133] L. Ferrucci, A. Cherubini, S. Bandinelli, et al., "Relationship of plasma polyunsaturated fatty acids to circulating inflammatory markers," Journal of Clinical Endocrinology and Metabolism, vol. 91, no. 2, pp. 439-446, 2006.

[134] M. A. Micallef, I. A. Munro, and M. L. Garg, "An inverse relationship between plasma n-3 fatty acids and C-reactive protein in healthy individuals," European Journal of Clinical Nutrition, vol. 63, no. 9, pp. 1154-1156, 2009.

[135] K. Murakami, S. Sasaki, Y. Takahashi, et al., "Total n3 polyunsaturated fatty acid intake is inversely associated with serum C-reactive protein in young Japanese women," Nutrition Research, vol. 28, no. 5, pp. 309-314, 2008.

[136] T. Pischon, S. E. Hankinson, G. S. Hotamisligil, N. Rifai, W. C. Willett, and E. B. Rimm, "Habitual dietary intake of n3 and n- 6 fatty acids in relation to inflammatory markers among US men and women," Circulation, vol. 108, no. 2, pp. 155-160, 2003.

[137] P. M. Ridker and D. A. Morrow, "C-reactive protein, inflammation, and coronary risk," Cardiology Clinics, vol. 21, no. 3, pp. 315-325, 2003.

[138] R. Farzaneh-Far, W. S. Harris, S. Garg, B. Na, and M. A. Whooley, "Inverse association of erythrocyte n-3 fatty acid levels with inflammatory biomarkers in patients with stable coronary artery disease: the Heart and Soul Study," Atherosclerosis, vol. 205, no. 2, pp. 538-543, 2009.

[139] D. S. Kelley, D. Siegel, D. M. Fedor, Y. Adkins, and B. E. Mackey, "DHA supplementation decreases serum Creactive protein and other markers of inflammation in hypertriglyceridemic men," Journal of Nutrition, vol. 139, no. 3, pp. 495-501, 2009.

[140] O. P. Almeida, P. Norman, G. J. Hankey, K. Jamrozik, and L. Flicker, "The association between C-reactive protein concentration and depression in later life is due to poor physical health: results from the Health in Men Study (HIMS)," Psychological Medicine, vol. 37, no. 12, pp. 17751786, 2007.

[141] M. A. Bremmer, A. T. F. Beekman, D. J. H. Deeg, et al., "Inflammatory markers in late-life depression: results from a population-based study," Journal of Affective Disorders, vol. 106, no. 3, pp. 249-255, 2008.

[142] D. E. Ford and T. P. Erlinger, "Depression and C-reactive protein in US adults: data from the Third National Health and Nutrition Examination Survey," Archives of Internal Medicine, vol. 164, no. 9, pp. 1010-1014, 2004.
[143] M. A. Kling, S. Alesci, G. Csako, et al., "Sustained low-grade pro-inflammatory state in unmedicated, remitted women with major depressive disorder as evidenced by elevated serum levels of the acute phase proteins $\mathrm{C}$-reactive protein and serum amyloid A," Biological Psychiatry, vol. 62, no. 4, pp. 309-313, 2007.

[144] J. E. Piletz, A. Halaris, O. Iqbal, et al., "Proinflammatorybiomakers in depression: treatment with venlafaxine," The World Journal of Biological Psychiatry. In press.

[145] P. G. Surtees, N. W. Wainwright, S. M. Boekholdt, R. N. Luben, N. J. Wareham, and K. T. Khaw, "Major depression, $\mathrm{C}$-reactive protein, and incident ischemic heart disease in healthy men and women," Psychosomatic Medicine, vol. 70, no. 8, pp. 850-855, 2008.

[146] B. Bankier, J. Barajas, A. Martinez-Rumayor, and J. L. Januzzi, "Association between major depressive disorder and C-reactive protein levels in stable coronary heart disease patients," Journal of Psychosomatic Research, vol. 66, no. 3, pp. 189-194, 2009.

[147] M. A. Whooley, C. M. Caska, B. E. Hendrickson, M. A. Rourke, J. Ho, and S. Ali, "Depression and inflammation in patients with coronary heart disease: findings from the Heart and Soul Study," Biological Psychiatry, vol. 62, no. 4, pp. 314320, 2007.

[148] M. A. Austin, J. E. Hokanson, and K. L. Edwards, "Hypertriglyceridemia as a cardiovascular risk factor," American Journal of Cardiology, vol. 81, no. 4A, pp. 7B-12B, 1998.

[149] M. Haim, M. Benderly, D. Brunner, et al., "Elevated serum triglyceride levels and long-term mortality in patients with coronary heart disease: the Bezafibrate Infarction Prevention (BIP) registry," Circulation, vol. 100, no. 5, pp. 475-482, 1999.

[150] J. E. Hokanson and M. A. Austin, "Plasma triglyceride level is a risk factor for cardiovascular disease independent of high-density lipoprotein cholesterol level: a meta-analysis of population-based prospective studies," Journal of Cardiovascular Risk, vol. 3, no. 2, pp. 213-219, 1996.

[151] W. S. Harris, "Fish oils and plasma lipid and lipoprotein metabolism in humans: a critical review," Journal of Lipid Research, vol. 30, no. 6, pp. 785-807, 1989.

[152] W. S. Harris and D. Bulchandani, "Why do omega-3 fatty acids lower serum triglycerides?" Current Opinion in Lipidology, vol. 17, no. 4, pp. 387-393, 2006.

[153] J. M. McKenney and D. Sica, "Role of prescription omega3 fatty acids in the treatment of hypertriglyceridemia," Pharmacotherapy, vol. 27, no. 5, pp. 715-728, 2007.

[154] C. J. Glueck, M. Tieger, R. Kunkel, et al., "Improvement in symptoms of depression and in an index of life stressors accompany treatment of severe hypertriglyceridemia," Biological Psychiatry, vol. 34, no. 4, pp. 240-252, 1993.

[155] P. M. Kris-Etherton, W. S. Harris, and L. J. Appel, "Fish consumption, fish oil, omega-3 fatty acids, and cardiovascular disease," Circulation, vol. 106, no. 21, pp. 2747-2757, 2002.

[156] M. Peet, J. Brind, C. N. Ramchand, S. Shah, and G. K. Vankar, "Two double-blind placebo-controlled pilot studies of eicosapentaenoic acid in the treatment of schizophrenia," Schizophrenia Research, vol. 49, no. 3, pp. 243-251, 2001.

[157] R. N. Caniato, M. E. Alvarenga, and M. A. Garcia-Alcaraz, "Effect of omega-3 fatty acids on the lipid profile of patients taking clozapine," Australian and New Zealand Journal of Psychiatry, vol. 40, no. 8, pp. 691-697, 2006. 
[158] T.-L. Huang and J.-F. Chen, "Lipid and lipoprotein levels in depressive disorders with melancholic feature or atypical feature and dysthymia," Psychiatry and Clinical Neurosciences, vol. 58, no. 3, pp. 295-299, 2004.

[159] S. O. Olusi and A. A. Fido, "Serum lipid concentrations in patients with major depressive disorder," Biological Psychiatry, vol. 40, no. 11, pp. 1128-1131, 1996.

[160] D. S. Freedman, T. Byers, D. H. Barrett, et al., "Plasma lipid levels and psychologic characteristics in men," American Journal of Epidemiology, vol. 141, no. 6, pp. 507-517, 1995.

[161] J. J. M. H. Strik, R. Lousberg, H. J. G. M. Crijns, M. Maes, and A. Honig, "Relation of levels of serum lipoproteins to depression after acute myocardial infarction," American Journal of Cardiology, vol. 90, no. 12, pp. 1368-1370, 2002.

[162] O. P. Almeida, L. Flicker, P. Norman, et al., "Association of cardiovascular risk factors and disease with depression in later life," American Journal of Geriatric Psychiatry, vol. 15, no. 6, pp. 506-513, 2007.

[163] J. J. Freiberg, A. Tybjærg-Hansen, J. S. Jensen, and B. G. Nordestgaard, "Nonfasting triglycerides and risk of ischemic stroke in the general population," Journal of the American Medical Association, vol. 300, no. 18, pp. 2142-2152, 2008.

[164] S. Mora, N. Rifai, J. E. Buring, and P. M. Ridker, "Fasting compared with nonfasting lipids and apolipoproteins for predicting incident cardiovascular events," Circulation, vol. 118, no. 10, pp. 993-1001, 2008.

[165] E. S. Ford, W. H. Giles, and W. H. Dietz, "Prevalence of the metabolic syndrome among US adults: findings from the Third National Health and Nutrition Examination Survey," Journal of the American Medical Association, vol. 287, no. 3, pp. 356-359, 2002.

[166] J. Cao, K. A. Schwichtenberg, N. Q. Hanson, and M. Y. Tsai, "Incorporation and clearance of omega-3 fatty acids in erythrocyte membranes and plasma phospholipids," Clinical Chemistry, vol. 52, no. 12, pp. 2265-2272, 2006. 


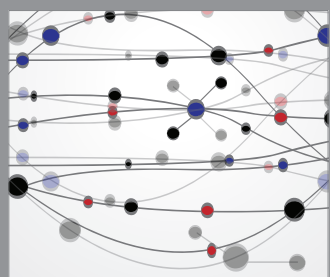

The Scientific World Journal
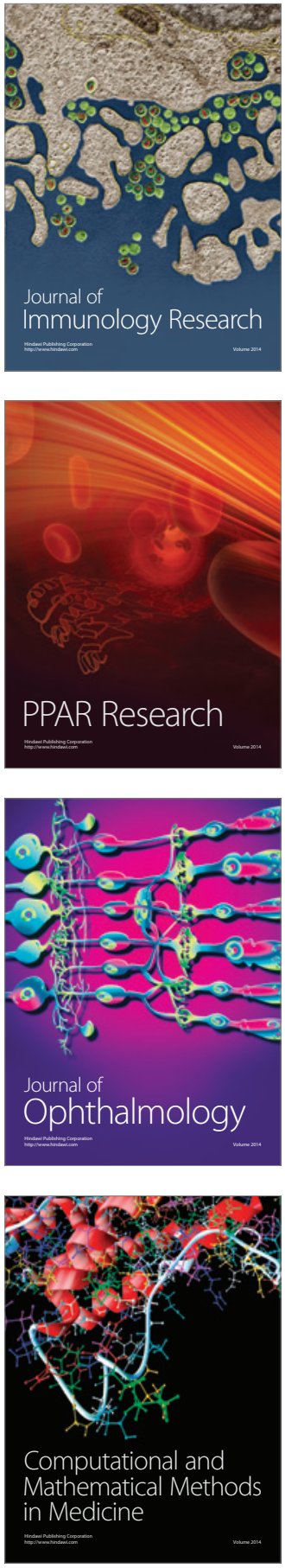

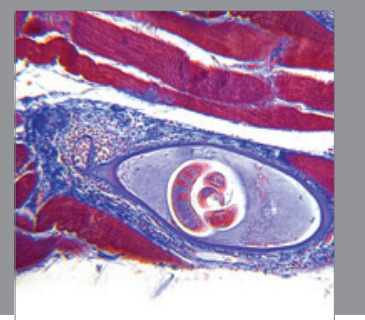

Gastroenterology

Research and Practice
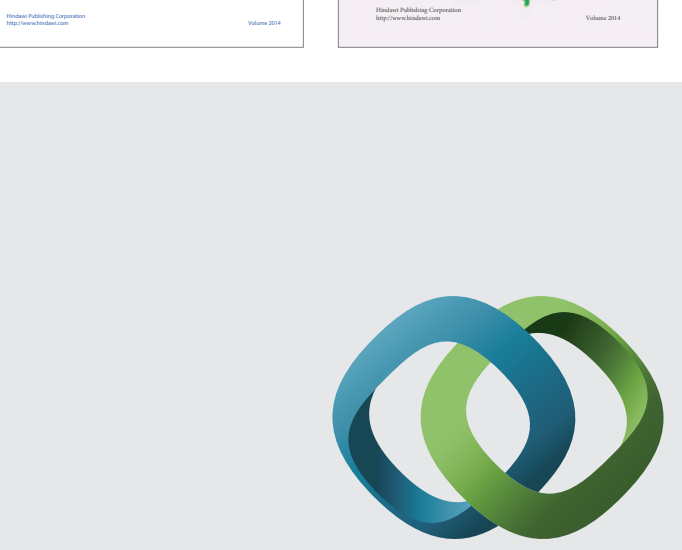

\section{Hindawi}

Submit your manuscripts at

http://www.hindawi.com
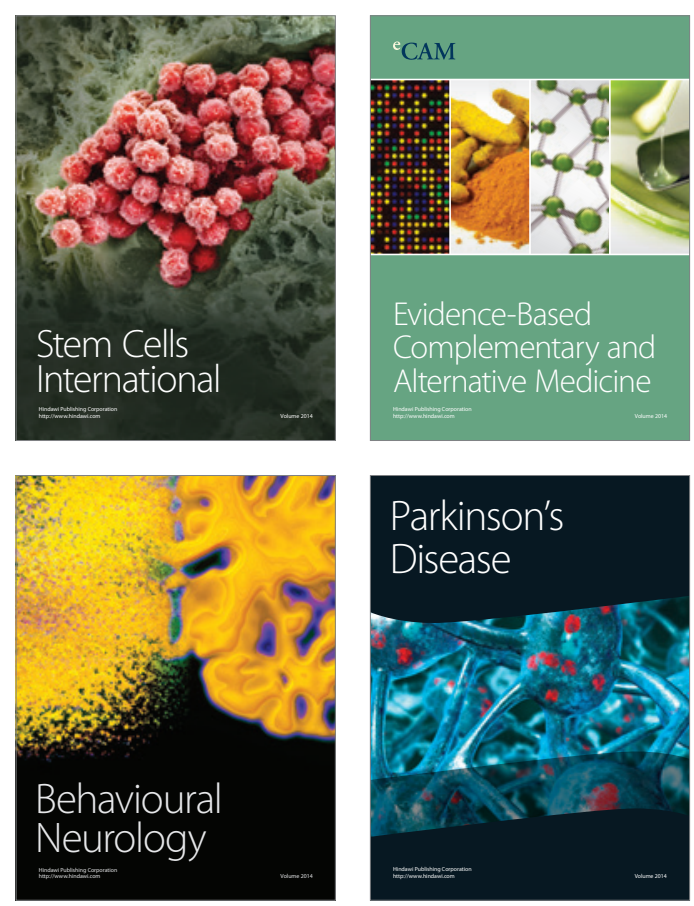

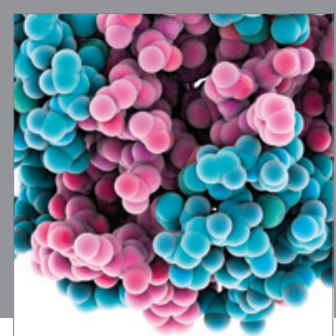

Journal of
Diabetes Research

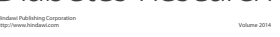

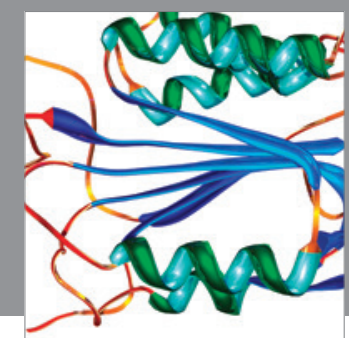

Disease Markers
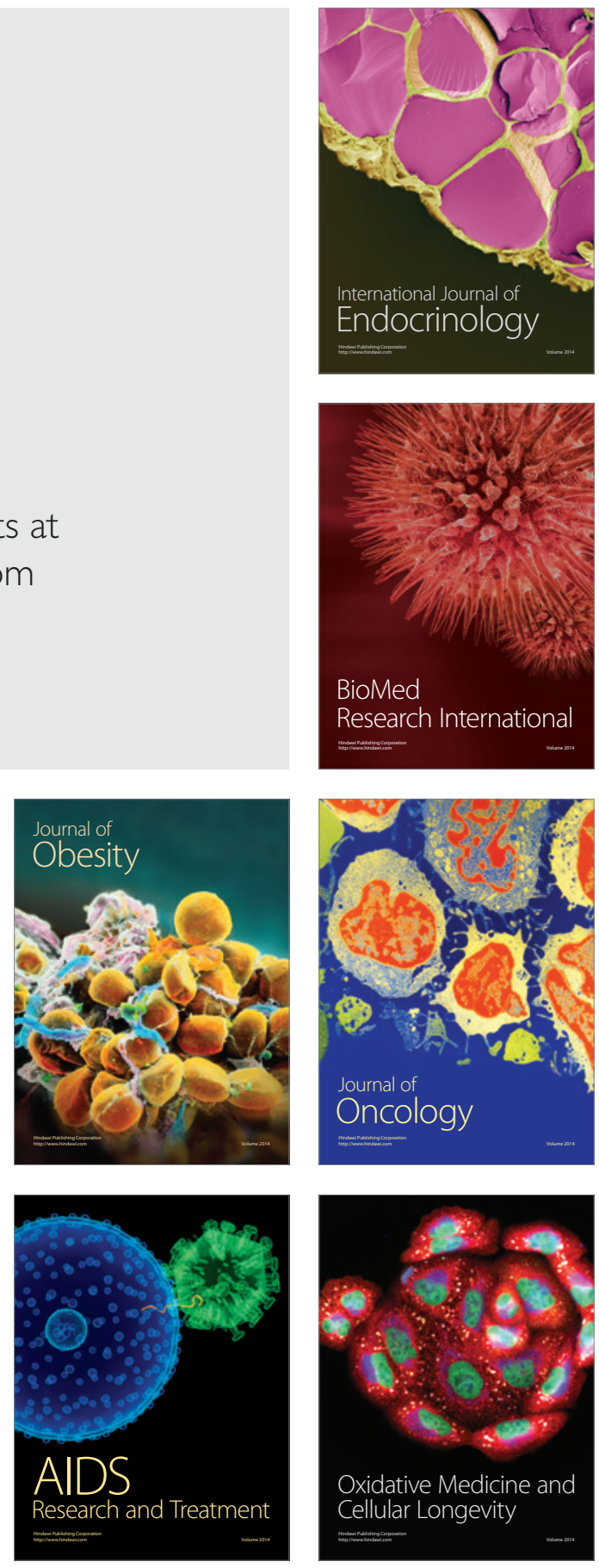